\title{
UTILIZAÇÃO DE MESOCARPO DE COCO MODIFICADO QUIMICAMENTE PARA TRATAMENTO DE EFLUENTE TÊXTIL
}

\author{
G. H. G. SCARPONI ${ }^{1}$, e D. C. CARVALHO ${ }^{1}$ \\ ${ }^{1}$ Centro Universitário de Patos de Minas, Faculdade de Engenharia Química \\ E-mail para contato: gustavo.scarponi@outlook.com
}

\begin{abstract}
RESUMO - A indústria têxtil é a responsável pela liberação de efluentes contaminados com corantes e, quando não tratados corretamente, os mesmos são poluidores do ecossistema. Existem diversos métodos visando à remoção de corantes dos rejeitos da indústria têxtil, o uso de bioadsorventes, por exemplo pode ser um deles. O objetivo deste trabalho foi avaliar a eficiência de remoção do mesocarpo de coco da Bahia no tratamento de efluentes têxtil, sendo realizados testes modificados com ácido clorídrico $(\mathrm{HCl})$ variando massa $(0,01 \mathrm{e} 0,5 \mathrm{~g}) \mathrm{pH}(3$ e 9) e tempo (5 a 60min). Realizou-se planejamento fatorial de $2^{3}$ com ponto central. O mesocarpo modificado apresentou eficiência de remoção, sendo de $88,24 \%$, podendo assim ser empregados no tratamento de efluentes têxteis, substituindo ou sendo acrescentado aos tratamentos, reduzindo assim, o uso de reagentes químicos. Neste sentido, novos estudos devem ser realizados para determinação de valores ótimos.
\end{abstract}

\section{INTRODUÇÃO}

Nos dias atuais é muito comum, nos meios de comunicação, notícias referentes a problemas com águas. A atividade industrial é uma das principais responsáveis por gerar um volume significativo de resíduos, contendo diversas espécies nocivas à saúde humana e ao ambiente natural. Geralmente, esses resíduos são líquidos que necessitam de tratamento prévio antes de serem descartados em águas correntes e/ou solos (Brasil et al. 2007).

Entre os vários setores existentes nas indústrias têxtil, o setor de acabamento dos vestuários merece destaque, pois utiliza grandes quantidades de águas e de produtos químicos; produzindo elevados volumes de efluentes (Cardoso et al. 2004). Os efluentes provenientes da indústria têxtil têm como característica principal a presença de cor, resultado dos corantes que são aplicados nas operações de tingimento (Zollinger, 1987). Esta interfere na transmissão de luz solar para dentro da corrente de água e, prejudica a atividade fotossintética das plantas presentes nesse ecossistema. Além disso, a oxidação biológica desse material consome o oxigênio existente, dificultando a atividade respiratório dos organismos vivos presentes neste habitat, e consequentemente causando o aumento da demanda bioquímica de oxigênio (Silveira et al. 1990). 
Os tratamentos para estes efluentes utilizam produtos químicos que podem caso mal manuseados, aumentar os problemas ambientais e terem grande carga tóxica. (Avelar et al. 2010).

Uma boa proposta de tratamento para esses resíduos poluentes seria o processo de tratamento utilizando adsorção dos corantes presentes nos efluentes têxtis empregando biomaterias (Oliveira et al. 2011). Alguns tipos de materiais renováveis e de baixo custo vêm sendo estudados para possíveis utilizações, dentre eles estão os resíduos agroindustriais, disponíveis em grande quantidade. Estes são uma alternativa viável tanto do ponto de vista econômico como ambiental (Avelar et al. 2010).

Assim, o objetivo desta pesquisa foi avaliar o mesocarpo de coco modificado com HCL na remoção do corante azul de metileno presente no efluente têxtil. Para isso, foram avaliados a influência de $\mathrm{pH}$, velocidade de agitação, massa e o tempo de contato do resíduo com o efluente na eficiência de adsorção, bem como verificar o custo benefício dos resíduos agroindustriais para as indústrias e observar se após o tratamento com o resíduo os efluentes seguem a legislação de descarte.

\section{MATERIAIS E MÉTODO}

\subsection{Obtenção da biomassa e armazenamento do efluente}

O efluente utilizado foi coletado em uma indústria têxtil, localizada na cidade de Patos de Minas-MG e armazenado em galões de polietileno, ao abrigo de luz e calor. Os cocos utilizados foram disponibilizados por vendedores da mesma cidade e encaminhados para o Laboratório de Engenharia Química (LEQ) do Centro Universitário de Patos de MinasUNIPAM.

\subsection{Preparação do material adsorvente modificado com $\mathrm{HCl}$}

Após a obtenção do material, o mesmo foi desfibrado, obtendo-se o mesocarpo, e dispostos à secagem natural por aproximadamente 24 horas. Logo após, foram dispostos em um secador de bandeja (Desidratador Pardal ${ }^{\circledR}$ PE 60) com circulação de ar forçada, para uma secagem a temperatura de $70^{\circ} \mathrm{C}$, onde permaneceram por aproximadamente 48 horas.

Posteriormente as amostras foram trituradas em moinho de facas (Moinho de Willey) e passadas por um processo de peneiramento, onde o material de granulometria igual a 48 mesh foi utilizado.

Após a secagem e trituração, $15 \mathrm{~g}$ de mesocarpo de coco foram pesadas em balança analítica (Shimadzu), e misturados com $300 \mathrm{~mL}$ de $\mathrm{HCl}$ à 1,0 M. A homogeneização da amostra foi realizada em mesa agitadora (Quimis), durante 1 hora e agitação de $100 \mathrm{rpm}$. A dispersão passou por filtração simples, e o material úmido foi levada com água destilada e seco em estufa a $40^{\circ} \mathrm{C}$ por 72 horas.

\subsection{Determinação do ponto de carga zero}


Para encontrar o ponto de carga zero foram preparadas soluções a partir de diluição de ácido clorídrico, obtendo-se concentrações de 1 mol. $\mathrm{L}^{-1}$ e 0,1 mol. $\mathrm{L}^{-1}$ e básicas a partir da diluição de hidróxido de sódio, obtendo-se as concentrações de 1 mol.L $\mathrm{L}^{-1}$ e 0,1 mol.L ${ }^{-1}$. pH's foram ajustados a partir das soluções nas faixas de 1 a $11 \mathrm{com}$ auxílio do pHmetro (Tecnal ${ }^{\circledR}$ TEC2). Posteriormente, foram misturados em frasco de polietileno, aproximadamente $0,10 \mathrm{~g}$ de biomassa com $10 \mathrm{~mL}$ de solução sob as diferentes condições de $\mathrm{pH}$ inicial citados acima. Após 24 horas foi aferido o $\mathrm{pH}$ final.

\subsection{Planejamento fatorial}

As condições experimentais para adsorção da cor do efluente foram determinadas por meio de planejamento fatorial experimental a fim de obter as condições ótimas do experimento. As variáveis analisadas foram: $\mathrm{pH}$ da solução, tempo de contato (minutos) e massa (gramas) como segue na Tabela 1.

Tabela 1 - Variáveis e níveis estudados no planejamento fatorial.

\begin{tabular}{|c|c|c|c|}
\hline \multirow{2}{*}{ Variáveis } & \multicolumn{3}{|c|}{ Níveis } \\
\cline { 2 - 4 } & - & 0 & + \\
\hline \hline $\mathrm{pH}$ & 3,0 & 6,0 & 9,0 \\
\hline Massa adsorvente (g) & 0,01 & 0,26 & 0,50 \\
\hline Tempo (min) & 5,0 & 18,0 & 60,0 \\
\hline
\end{tabular}

Assim sendo caracterizado como um experimento fatorial de $2^{3} \mathrm{o}$ qual foram realizados em triplicata, em regime batelada como mostra na Tabela 2.

Tabela 2 - Condições ótimas de operação para cada experimento.

\begin{tabular}{|c|r|r|r|}
\hline Ensaio & Massa & $\mathrm{pH}$ & Tempo \\
\hline \hline 1 & -1 & -1 & -1 \\
\hline 2 & 1 & -1 & -1 \\
\hline 3 & -1 & 1 & -1 \\
\hline 4 & 1 & 1 & -1 \\
\hline 5 & -1 & -1 & 1 \\
\hline 6 & 1 & -1 & 1 \\
\hline 7 & -1 & 1 & 1 \\
\hline 8 & 1 & 1 & 1 \\
\hline 9 & 0 & 0 & 0 \\
\hline 10 & 0 & 0 & 0 \\
\hline 11 & 0 & 0 & 0 \\
\hline
\end{tabular}

Para o estudo fatorial foram adicionados 0,01 e 0,5 gramas de amostra em $25 \mathrm{~mL}$ de efluente. Os valores de $\mathrm{pH}$ ( 3 e 9) foram corrigidos e ajustados com $\mathrm{HCl}$ e $\mathrm{NaOH}$, ambos em 
0,1M com auxílio do pHmetro (Tecnal® TEC2). Os ensaios de 9 a 11 foram realizados com os valores médios de massa, $\mathrm{pH}$ e tempo.

\subsection{Avaliação da remoção de corante do efluente}

As análises do filtrado obtido do tratamento com as amostras, foram realizadas por espectrofotômetro UV-VIS (Thermo Spectronic), a fim de verificar a remoção da cor. A capacidade adsortiva do material foi mensurada através da Equação 1.

$$
\text { Descoloração } \%=\frac{\left(A_{\text {bai }}-A_{\text {mo }}\right) \times 100}{A_{\text {bai }}}
$$

Em que:

$A_{\text {bai }}=$ Absorbância do efluente bruto

$\mathrm{A}_{\mathrm{mo}}=$ Absorbância da amostra

O cálculo de percentagem de remoção foi utilizado durantes os testes o que assegura que as variações são relacionadas apenas com a remoção e não a variação de leitura diária do aparelho.

Os cálculos de efeito dos fatores: $\mathrm{pH}$, massa e tempo e as interações entre elas com os seus respectivos erros padrão foram realizados com o auxílio do programa Statistica $13.0^{\circledR} \mathrm{e}$ os dados obtidos foram plotados no gráfico de Pareto com suas com suas respectivas interações e no gráfico de superfície.

\section{RESULTADOS E DISCUSSÕES}

\subsection{Ponto de carga zero}

Primeiramente, obteve-se a caracterização do ponto de carga zero (PCZ). Os resultados foram expressos por meio do gráfico de $\mathrm{pH}$ inicial versus $\mathrm{pH}$ final, sendo que $\mathrm{pH} \mathrm{PCZ}_{\mathrm{PC}}$ correspondente à faixa em que o $\mathrm{pH}$ final se mantiver constante (independente do $\mathrm{pH}$ inicial). A determinação do pHPCZ nos testes preliminares de biossorção é fundamental para a caracterização do absorvente em estudo, já que o pH da solução e do pHPCZ do adsorvente são fatores importantes no processo, especialmente na capacidade de adsorção.

$\mathrm{O} \mathrm{pH}_{\mathrm{PCZ}}$ é o valor de $\mathrm{pH}$ que corresponde ao equilíbrio entre as cargas superficiais positivas e negativas do adsorvente, ou seja, é o valor no qual a carga de superfície do adsorvente é nula (Wang et al. 2005).

Através da Figura 1 foi possível observar que a faixa de $\mathrm{pH}$ permaneceu constante ente 4,0 e 9,0 aproximadamente. Em $\mathrm{pH}$ maiores que 9,0 o mesocarpo modificado com $\mathrm{HCl}$ apresenta-se negativamente carregado, possuindo habilidades de adsorver espécies positivamente carregadas. O contrário acontece para pH's menores que 4,0.

Figura 1 - Ponto de carga zero do mesocarpo modificado com $\mathrm{HCl}$ 


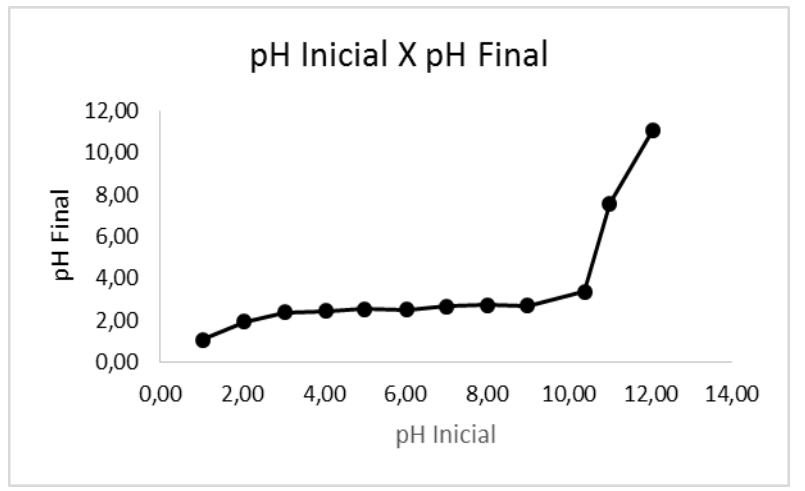

\subsection{Planejamento fatorial}

As respostas dos efeitos dos fatores e suas interações são mostradas através do Diagrama de Pareto (Figura 2) para o mesocarpo modificado com $\mathrm{HCl}$.

Figura 2 - Diagrama de Pareto do mesocarpo modificado com $\mathrm{HCl}$

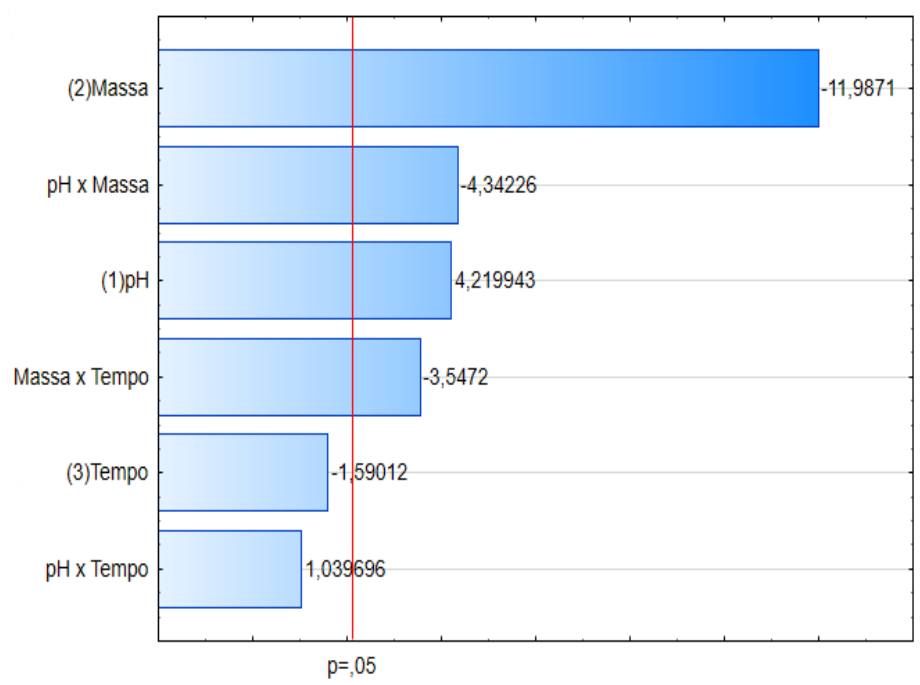

Analisando-se os dados experimentais, observa-se que os parâmetros estudados, apenas; massa, $\mathrm{pH} \mathrm{X}$ massa, $\mathrm{pH}$, massa $\mathrm{X}$ tempo foram significativos.

O valor negativo no diagrama de Pareto para massa significa que à medida que diminuí a quantidade de massa de adsorvente, obtém-se um aumento na capacidade de adsorção. $\mathrm{O}$ valor positivo para $\mathrm{pH}$, indica que à medida que o $\mathrm{pH}$ aumenta, a remoção de corante será melhor.

A interação massa $X$ tempo apresentou sinal negativo, o que representa que se houver uma diminuição de ambos, obtém-se uma melhor remoção. Assim sendo também para pH X massa.

Após a avaliação do Diagrama de Pareto foi plotado um gráfico de superfície para avaliar as tendências dos resultados obtidos no planejamento, abaixo segue a Figura 3.

Figura 3 - Gráfico de superfície do mesocarpo modificado com $\mathrm{HCl}$ 


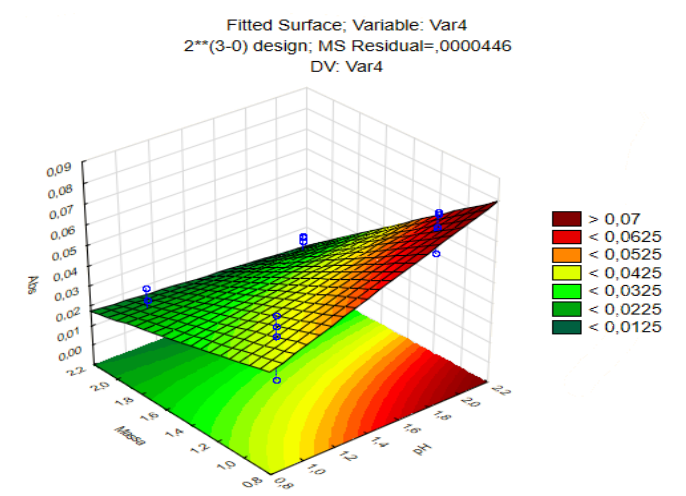

A Figura 3 demonstra que há uma tendência de melhor remoção do corante têxtil no efluente, em maiores valores de $\mathrm{pH}$ do que o testado $(\mathrm{pH} 9,0)$ e em quantidades menores que $0,01 \mathrm{~g}$ de massa de adsorvente.

\section{CONCLUSÃO}

Ao analisar o poder de adsorção de azul de metileno por rejeito fibroso de coco da Bahia, foi possível investigar a influência das variáveis de processo: massa, tempo e $\mathrm{pH}$, através da utilização do planejamento experimental $2^{3}$. Sendo a máxima capacidade adosrtiva alcançada com 0,5g de massa, tempo de agitação 60 minutos e pH 3,0. Sendo que o mesocarpo de coco se mostrou uma alternativa promissora e viável para a remoção de corante, tendo em vista que este adsorvente é abundante e de baixo custo quando comprado a adsorvente químicos.

\section{REFERÊNCIAS}

AVELAR, F. F.; BIANCHI, M. L; GONÇALVES, M.; MOTA, E. G. The use of piassava fibers (Attalea funifera) in the preparation of activated carbono. Bioresource Technology. Essex, v. 101, n. 12, p. 4639-4654, 2010.

BRASIL, JORGE L. et al. Planejamento estatístico de experimentos como uma ferramenta para otimização das condições de biossorção de Cu(II) em batelada utilizando-se casca de nozes pecã como bioadsorvente, Porto Alegre, v.30, n.3, p.548-553, 2007.

CARDOSO, M.H; RAMALHO, P. Biodegradação de corantes de efluentes têxteis por leveduras. Universidade do Minho, 2004.

OLIVEIRA, R; SILVA, R. C. O. Biossorção de cromo (VI) utilizando cacas de jabuticaba. 2011. 36 f. Trabalho de Conclusão de Curso (Bacharel em Química) - Curso de Bacharelado em Química, Universidade Tecnológica Federal do Paraná, Pato Branco.

SILVEIRA, S. S. B.; SANTANNA, F. S. P. Poluição Hídrica. Meio ambiente: aspectos técnicos e econômicos. Brasília PNDU/IPEA, p. 57-84, 1990.

WANG, S. et al. The physical and surface chemical characteristics of actived carbons and the adsorption of methyleno blue from wastewater. Journal of Colloid and Interface Science, v. 284, n. 2, p. 440-446, abr. 2005.

ZOOLLINGER, H. Color chemistry - Syntheses, properties and applications of organic dyes pigments. New York, NY: VCH. p. 83-148. 1987. 